\title{
EL REAL COLEGIO MAYOR DE SAN CLEMENTE DE LOS ESPAÑOLES DE BOLONIA Y LA MONARQUÍA HISPÁNICA
}

\author{
Maria Cristina Pascerini \\ (Instituto Universitario La Corte en Europa-Universidad Autónoma de Madrid)
}

\section{RESUMEN}

El Colegio de San Clemente de Bolonia, fundado por el cardenal Egidio Álvarez de Albornoz y Luna en 1364, no solo sirvió de modelo para los demás Colegios Mayores españoles, sino que fue una verdadera cantera de funcionarios para la Monarquía hispánica. La Real Protección fue otorgada al Colegio ya por los Reyes Católicos, y quedó recogida en sus Estatutos a partir de 1488. Carlos V concedió su protección al Colegio en 1530 estando en Bolonia, ciudad en la que fue coronado emperador por el papa Clemente VII. Todos los monarcas de la casa de Habsburgo renovaron la protección, y así también lo hizo Felipe $\mathrm{V}$ de Borbón, quien visitó el Colegio en 1702. A partir del siglo XVIII hubo en el Colegio visitadores de nombramiento regio, y con los Estatutos de 1876 la Monarquía española se convirtió en la autoridad a quien competen la conservación, protección y alto patrocinio del Colegio.

PALABRAS CLAVE: Real Colegio Mayor de San Clemente de los Españoles de Bolonia - Universidad de Bolonia - Monarquía hispánica - Carlos V - Felipe V.

\section{THE SPANISH COLLEGE AT BOLOGNA AND THE HISPANIC MONARCHY}

\begin{abstract}
The Spanish College at Bologna, founded by Cardinal Egidio Álvarez de Albornoz y Luna in 1364, not only served as a model for all the Spanish Colleges, but also became a true quarry of civil servants for the Hispanic Monarchy. The Royal Protection was first granted to the College by the Catholic Monarchs, and is established in its Rules since 1488. Charles V granted his protection to the College during his stay in Bologna, where he was crowned as emperor by the pope Clemente VII. All the kings of the house of Habsburg renewed their protection, as well as King Philip V did. He also visited the College in 1702. Since the $18^{\text {th }}$ century there were visitors designed by the king in the College, and, with the Rules of 1876 the Hispanic Monarchy became the authority with domain on the conservation, protection and high sponsorship of the College.
\end{abstract}


KEY WORDS: Spanish College at Bologna - University of Bologna - Hispanic Monarchy - Charles V - Philip V.

\section{LA VISITA DEL REY JUAN CARLOS}

La importancia de la relación entre el Colegio de San Clemente de Bolonia y la Monarquía española fue subrayada por las palabras que el Rey Juan Carlos de Borbón pronunció en el Aula Magna de la Universidad de Bolonia al recibir la distinción de Doctor honoris causa en Jurisprudencia por esta Universidad en 1988, año en que la institución celebraba su Noveno Centenario:

Italianos y españoles, junto a otros pueblos de Europa, nos sabemos hermanos en la latinidad. Un substrato común de derecho romano determina grandes semejanzas en nuestra manera de entender y vivir las relaciones interpersonales, desde la intimidad de la familia hasta el perfil de las instituciones públicas. [...] ese derecho los españoles, como los mismos italianos, lo aprendimos en Bolonia. ${ }^{1}$

En aquella ocasión don Juan Carlos mencionó que fue el ejemplo de la Universidad de Bolonia el que estimuló la creación de las primeras universidades españolas: la de Palencia, la de Valladolid y la de Salamanca, y resaltó también «la afluencia ininterrumpida de estudiosos españoles a Bolonia», ciudad en la que los estudiantes aprendían derecho. Esto favoreció el acercamiento de sistemas jurídicos diferentes en los reinos medievales de la Península: «en la medida en que sus distintos ordenamientos adoptaban el derecho ejemplar mostrado por Bolonia, se aproximaban entre sí; y no por imposiciones externas, sino por un impulso autónomo» ${ }^{2}$. En Bolonia no solo se originó un acercamiento jurídico, sino que para los estudiantes hispanos empezó una vida en común en una casa común, esto es el Colegio de San Clemente: «los orígenes de la unidad hispánica tienen otra connotación boloñesa no menos patente; porque, en algún modo, esa unidad se ensayó aquí por primera vez» ${ }^{3}$. Para subrayar el profundo vínculo entre el Colegio y España, el Rey afirmaba:

los boloñeses y los españoles podemos enorgullecernos en común de esta institución sin par, pues quizá no haya en todo el mundo otro ejemplo de unos vínculos históricos tan hondos y constantes entre una ciudad y una nación extranjera como los que representa el Real Colegio ${ }^{4}$.

\footnotetext{
${ }^{1}$ Los reyes de España en Bolonia (Bolonia: Real Colegio de España, 1988), 7.

2 Ibídem, 11.

${ }^{3}$ Ibídem, 11.

4 Ibídem, 11-12.
} 
En ocasión de la misma visita a Bolonia, don Juan Carlos confirmaba en el edificio del Real Colegio la protección que desde 1488 los reyes de la Monarquía hispánica habían otorgado al Colegio, cuya fundación se debió a la voluntad de Gil de Albornoz ${ }^{5}$, quien fuera arzobispo de Toledo.

\section{LA FUNDACIÓN DEL COLEGIO}

Gil de Albornoz bien conocía la importancia del estudio del Derecho en Bolonia $^{6}$ a su paso por la ciudad en 1360 como legado papal $^{7}$, y en su testamento fechado en $1364^{8}$ dispuso que con parte de sus bienes se construyera en Bolonia un

\footnotetext{
${ }^{5}$ Egidio Álvarez de Albornoz y Luna, conocido como Gil de Albornoz, nació en Cuenca en 1302 de Garci Álvarez de Albornoz y Teresa Martínez de Luna, hermana de Jimeno Martínez de Luna, obispo de Zaragoza y luego arzobispo de Toledo. Albornoz empezó su formación en Zaragoza, y luego pasó a estudiar Leyes en la Universidad de Tolosa en Francia, donde pudo conocer a Étienne Aubert (el futuro papa Inocencio VI desde 1352 hasta 1362). A su vuelta a Castilla, Albornoz inició su carrera eclesiástica como arcediano de la Orden de Calatrava, siendo finalmente elegido en 1338 arzobispo de Toledo. En 1350 se exilió a Aviñón, donde fue acogido por el papa Clemente VI (13421352), que le nombró cardenal presbítero de San Clemente. En 1354 Albornoz fue enviado por el papa Inocencio VI a Roma para que resolviera la grave situación de desorden en la que se encontraba la ciudad. Una vez restablecido el orden en Roma, Albornoz se centró en la recuperación tanto militar como política del Patrimonio de San Pedro y, después de haber sido nombrado en 1356 cardenal obispo de Sabina (Roma), en 1357 promulgó las Constitutiones Aegidianae para la organización y gobierno del territorio pontificio. Falleció en Viterbo en 1367. Varios estudios sobe la figura de Albornoz se encuentran en El Cardenal Albornoz y el Colegio de España I, Edición y Prólogo de Evelio Verdera y Tuells, Studia Albornotiana XI (Bolonia: Real Colegio de España, 1972).

${ }^{6}$ El emplazamiento del Colegio de San Clemente fue establecido en la zona de Bolonia en la que entre el siglo XIII y el siglo XV estuvieron, según Francesco Cavazza, la mayoría de las scholae de Derecho de la ciudad. Véase Francesco Cavazza, Le scuole dell'antico Studio bolognese, Ristampa anastatica dell'edizione di Milano, 1896, eseguita per gentile concessione della Casa Editrice U. Hoepli di Milano (Sala Bolognese: Arnaldo Forni Editore, 1987), 68. Sobre el estudio de Derecho de la Universidad de Bolonia véase también: Albano Sorbelli, Storia della Università di Bologna, Volume I Il Medioevo (secc. XI-XV) (Bologna: Nicola Zanichelli Editore, 1944); Giovanni de Vergottini, Lo Studio di Bologna, l'Impero, il Papato, Ristampa dell'edizione dell’Università degli Studi di Bologna, 1954 (Spoleto: Centro Italiano di Studi sull'Alto Medioevo, 1996); Antonio I. Pini, Studio, università e città nel medioevo bolognese (Bologna: CLUEB, 2005).

${ }^{7}$ Las vicisitudes del Cardenal Albornoz se encuentran en la obra De rebus gestis Aegidij Albornotij de un alumno ilustre del Colegio, el cordobés Juan Genesio [Ginés] de Sepúlveda incluida en la Historia de bello administrato in Italia per annos XV \& confecto ab Illustriss. ac Reuerendiss. D.D. Aegidio Albornotio $S \cdot R \cdot E \cdot$ CARDINALI Pont. Max. Innocentij VI, qui Auenione tunc residebat, Legato. Sacri, \& perinsignis Collegij maioris S. Clemente Hispanorum, quod Bononiae est, Fundatore. Pro vindicandis in libertatem omnibus Urbibus, quae antea in ditiones erant, et imperio Sanctae Romanae Ecclesiae. A Ioanne Genesio Sepulveda Hispano eiusdem Collegijalumno scripta. BONONIAE MDCXXVIII. Typis Clementis Ferronij. Al De rebus gestis Aegidij Albornotij sigue una Brevis Collegiis Maioris S. Clementis Hispanorum Bononiae descriptio, et quorundam, quae ad ipsium pertinent commemoratio. La Historia está incluida en la Miscellanea que se encuentra en la Biblioteca Archiginnasio de Bolonia con Signatura 17 O III 1 (op. 04).

${ }^{8}$ Illustriss. Ac reverendiss. D. Aegidii Albornotii S.R.E. Cardinales Totius Italiae Legati, Archiepiscopi Toletani, ac Collegij maioris Hispanorum Bononiae fundati Institutoris Testamentum, Bononiae MDCXXVIII. Typis
} 
Colegio bajo la tutela de San Clemente papa y mártir, su primer título cardenalicio9, para que fueran allí a estudiar veinticuatro estudiantes, y que la Casa o Colegio se llamara domus Hispanica ${ }^{10}$.

La fundación del Colegio fue importante porque, según señala Dámaso de Lario, «serviría de modelo directo al artífice del Colegio Mayor de San Bartolomé de Salamanca y en ella se inspirarían también los fundadores de los demás Colegios Mayores españoles, todos ellos posteriores a la Institución de Albornoz» ${ }^{11}$. Los albaceas del Cardenal, es decir su sobrino Fernando Álvarez de Albornoz y el capellán Alfonso Fernández, procedieron entre 1365 y 1368 a la compra de terrenos cercanos a las escuelas de Leyes y Teología de la Universidad de Bolonia. En el mismo año 1365 empezaron las obras del edificio según los planos de Matteo Gattaponi da Gubbio, que duraron dos años. El edificio original, terminado en mayo de 1367, se componía de cuatro edificios llamados palatii dispuestos en cuadrado alrededor de un patio interior, en uno de los cuales se situaba la capilla dedicada a San Clemente ${ }^{12}$. La muralla, ampliada y reforzada a principios del siglo XVI, pero que en origen tuvo que ser poco más que un muro de $\operatorname{cinta}^{13}$, dio al Colegio el característico aspecto de ciudadela dentro de la ciudad que todavía hoy conserva.

El cardenal Albornoz falleció en Viterbo en 1367 y no llegó a ver la construcción. Sus albaceas, según declararon el 12 de mayo de 1368 en Bolonia ${ }^{14}$,

Clementis Ferronij. Obra incluida en la Miscellanea que se encuentra en la Biblioteca Archiginnasio de Bolonia con Signatura 17 O III 1 (op. 05). La Biblioteca de Derecho de la Universidad Complutense de Madrid conserva la edición del testamento impresa en Bolonia en 1855 también reproducida digitalmente. En el archivo del Colegio de Bolonia se encuentra el original del testamento de Albornoz fechado en el Castillo Papal de San Cataldo de Ancona a 29 de septiembre de 1364, considerado el acto de fundación del Colegio de España.

${ }^{9}$ Gil de Albornoz fue nombrado por el papa Clemente VII cardinal presbítero de San Clemente, título que ostentó entre 1350 y 1356.

${ }^{10}$ Sobre el tema del Colegio y su fundador Gil de Albornoz véase Manuel Parada López de Corselas (ed.), Domus hispánica. El Real Colegio de España y el cardenal Gil de Albornoz en la Historia del Arte (Bologna: Bononia University Press, 2018).

${ }^{11}$ Dámaso de Lario, "Sobre los orígenes del burócrata moderno. El Colegio de San Clemente de Bolonia durante la impermeabilización habsburguesa (1568-1659)", Studia Albornotiana XLIII (Bolonia: Real Colegio de España, 1980): 25. Véase también Francisco Martín Hernández, "Influencia del Colegio de San Clemente de Bolonia en los Colegios mayores españoles", en El Cardenal Albornoz. y el Colegio de España II, Edición y Prólogo de Evelio Verdera y Tuells, Studia Albornotiana XI (Bolonia: Real Colegio de España, 1972): 239-260; y también Francisco Martín Hernández, "La influencia de los Colegios mayores españoles en la fundación y primer desarrollo de los americanos", en Estudios de historia social y económica de América, no 16-17 (1998): 9-22.

${ }^{12}$ Ignacio González-Varas Ibáñez en el volumen Dietro il muro del Collegio di Spagna (Bologna: CLUEB, 1998), 32-34.

13 Giuseppe Marchini, "Il Collegio di Spagna, edificio monumentale", en Studia Albornotiana XXXVI (Bolonia: Real Colegio de España, 1979): 23.

${ }^{14}$ Antonio Pérez Martín, Proles Aegidiana vol. I., Studia Albornotiana XXXI (Bolonia: Real Colegio de España, 1979): 18. 
llevaron a cabo los estatutos ${ }^{15}$, que sufrieron en el curso de los siglos varias modificaciones. Según Dámaso de Lario, el comienzo de las relaciones entre el Colegio y la Universidad de Bolonia se remite al año $1369^{16}$. Pedro Borrajo y Hermenegildo Giner de los Ríos, en su ensayo de 1880 titulado El Colegio de Bolonia. Centón de noticias relativas a la fundación hispana de San Clemente ${ }^{17}$, recuerdan en cambio los privilegios concedidos al Colegio por el Senado de Bolonia, que no solo lo eximió del pago de toda clase de gabela y contribución municipal, sino que permitió que el edificio quedara exento de número por ser considerado territorio español ${ }^{18}$.

En otoño del año 1368 empezaron a llegar al Colegio los primeros estudiantes. Según los Estatutos, podían ser admitidos a estudiar en él solo los estudiantes originarios de la Hispania entendida a la manera antigua, es decir la

15 Según anota Antonio Pérez Martín, los primeros estatutos conocidos son de 1377, y se encuentran en un Manuscrito del siglo XV de la Colección John D. Gordan de New York y en un incunable de 1485 conservado en el Museo Británico de Londres. Han sido estudiados respectivamente por Berthe Marie Marti y por Vicente Beltrán de Heredia (Pérez Martín, Proles Aegidiana vol. I., nota 62 p. 30 y nota 113 p. 39). El mismo autor cuida un breve estudio sobre la evolución de los estatutos (Pérez Martín, Proles Aegidiana vol. I., 28-39). Un estudio comparativo entre los estatutos de 1485, 1488 y 1522 ha sido llevado a cabo por Baltasar Cuart Moner, "Los Estatutos del Colegio de San Clemente como fuente para una aproximación al estudio de la burocracia (14851558)", en El Cardenal Albornoz y el Colegio de España IV, Studia Albornotiana XXXV (Bolonia: Real Colegio de España, 1979): 579-696.

Miquel Batllori registra estas cuatro ediciones de los estatutos (Statuta Collegii Hispanorum Bononiae): las de 1558, de 1628, de 1648 y 1668, en Miquel Batllori S.I., "El Colegio de España en Bolonia a fines del siglo XVIII" Studia albornotiana XII (Bolonia: Real Colegio de España, 1972): nota 1 p. 641. En la Biblioteca Archiginnasio de Bolonia se encuentran los estatutos publicados en 1628 bajo el título Statuta Sacri et Perinsignis Collegii Maioris S. Clementis Hispanorum Bononiae conditi, BONONIAE M.DC:XXVIII. Typis Clementis Ferronij, incluidos en la Miscelanea que se encuentra en dicha Biblioteca con Signatura 17 O III 1 (op. 06). En la Biblioteca Nacional de España se conservan los estatutos publicados en 1648 en el volumen BNE, 2/56002: Statuta Collegii Maioris S. Cleme. que reúne distintas publicaciones relacionadas con el Colegio de San Clemente: Statuta almi et perinsignis Collegii Maioris Sancti Clementis Hispanorum Bononiae conditi. Bononiae, M.DC.XLVIII. Ex Typographia Haeredis Benatij; Illustrissimi, ac Reverendiss · Aegidii Albornotii...Testamentum, Bononiae, Apud Victorium Benatium. MDCVIII; Ceremonias y Costumbres usadas y guardadas, Y que se deuen usar, y guardar en este Insigne Colegio Mayor de S. Clemente de los Españoles de Bolonia. En Bolonia, en la Imprenta de Pier Maria Monti. M.DCC.VI; Varias Cédulas Reales y Certificaciones.

Giancarlo Roversi señala que en el British Museum se deberían conservar los estatutos de 1485, en Giancarlo Roversi, "L'azione di papa Lambertini a favore del Collegio di Spagna e la controversa Visita apostolica del 1741", El Cardenal Albornoz y el Colegio de España, Studia albornotiana XII (Bolonia: Real Colegio de España 1972), nota 8 p. 531. Sobre los primeros estatutos véanse dos estudios: Berthe Marie Marti, The Spanish College at Bologna in the Fourteenth Century (Philadelphia, University of Carolina Press, 1966); y Vicente Beltrán de Heredia, Primeros estatutos del Colegio Español de S. Clemente en Bolonia, en «Hispania Sacra» 11 (1958): 409-426.

${ }^{16}$ Dámaso de Lario, "La Universidad de Bolonia y el Colegio de España en el tránsito de los siglos XVI al XVII", en Estudis: Revista de historia moderna, no 8 (1979-1980): 7.

${ }^{17}$ Pedro Borrajo y Herrera, Hermenegildo Giner de los Ríos, El Colegio de Bolonia. Centón de noticias relativas a la fundación bispana de San Clemente, por los excolegiales D. Pedro Borrajo y Herrera y D. Hermenegildo Giner de los Ríos (Madrid, 1880).

18 Ibídem, 9. 
comprendida entre los Pirineos y el mar. Al terminar sus estudios en San Clemente, los bolonios empezaban en su mayoría su carrera en la Administración civil o eclesiástica ${ }^{19}$, tanto que el Colegio se convirtió en un verdadero «vivero de funcionarios para la Monarquía hispánica» $»^{20}$.

Muchos colegiales pasaron por San Clemente ${ }^{21}$, y de ellos dio cuenta en 1629 el sevillano Juan de Pineda Hurtado de Mendoza en Proles Aegidiana ${ }^{22}$. También hubo estudiantes portugueses. Según António Domingues de Sousa Costa, autor de la obra en dos volúmenes Portugueses no Colégio de S. Clemente e Universidade de Bolonha durante o século XV (1990), su presencia estaba justificada en las especificaciones del testamento y de los estatutos más antiguos ${ }^{23}$, que preveían que entre los 24 colegiales hispanos del Colegio hubiese «uno de Portugal, más concretamente de la diócesis de Lisboa» ${ }^{24}$. Como confirmación de la presencia portuguesa en el Colegio se podría citar el caso, encontrado por Amando Represa en el Archivo de Simancas, de dos portugueses que en 1674 y 1675 pedían ser admitidos en el Colegio. El rector consultó al cardenal protector del colegio, quien se dirigió al rey. Éste a su vez interpeló al Consejo de Estado el cual, llamado a dirimir la cuestión, consultó los estatutos fundacionales, y deliberó que no se pusiese impedimento con tal de que el portugués «fuese afecto a la Corona y no sospechoso» ${ }^{25}$.

En 1979 Antonio Pérez Martín actualizó el citado trabajo de 1629 de Juan de Pineda Hurtado con un poderoso estudio en cuatro tomos que lleva el mismo título, Proles Aegidiana, y en el que se recogen los colegiales desde el año 1368 hasta el 1977. Pérez Martín afirma que «la autoridad del Rey sobre la institución albornociana, al

${ }^{19}$ Lario, "Sobre los orígenes del burócrata moderno", 182-183.

20 Antonio Domínguez Ortiz, "Prólogo" en Studia Albornotiana XLIII; y Lario, "Sobre los orígenes del burócrata moderno", 14.

${ }^{21}$ Sobre la extracción social de los estudiantes de S. Clemente véase Baltasar Cuart Moner, "Colegiales y burócratas: El caso del Colegio de San Clemente de los españoles de Bolonia en la primera mitad del s. XVI", en Studia histórica. Historia moderna, no 1 (1983): 65-93.

22 Proles Aegidiana seu Catalogus Illust. Virorum, Qui ex Almo, \& Perinsigni Collegio Maiori Sancti Clementis Hispanorum. Auspicijs bonae memoriae Illustriss. \& Reuerendiss. D.D. Aegidii S.R.E. Cardinalis Albornotij Episcopi Sabinensis, Archiepiscopi Toletani, \& totius Italiae Legati generalis, Bononiae condito buc usque in lucem prodiere. Opus sane curiosum: collectum a D. Ioanne de Pineda Hurtado de Mendoza Hispalensi, eiusdem Collegij alumno, \& institutionum Imperialium antecessore. BONONIAE, Apud Haeredem Bartholomaei Cochij, M.DC.XXIIII, Superiorum permissu.

23 Por lo menos hasta la reforma de 1876, según se desprende del estudio sobre los "Requisitos para ser admitido como colegial" llevado a cabo por Pérez Martín, Proles Aegidiana vol. I., 39-58.

24 António Domingues de Sousa Costa, Portugueses no Colégio de S. Clemente e Universidade de Bolonha durante o século XV, vol. I (Bolonia: Real Colegio de España, 1990), 16. Otro trabajo de Federigo Melis, "Sul finanziamento degli allievi portoghesi del Real Colegio di Spagna di Bologna nel XV secolo", en El Cardenal Albornozy el Colegio de España III, Studia Albornotiana XIII (Bolonia: Real Colegio de España, 1973): 419-434, investiga las formas de financiación de los estudiantes portugueses del Colegio en el siglo XV a través del estudio de las cartas de cambio de las sociedades banqueras florentinas y de sus filiales en Lisboa.

25 Amando Represa, "El Colegio Español de Bolonia, según la documentación de Simancas", Studia Albornotiana XII (Bolonia: Real Colegio de España, 1972): 397. 
principio inexistente, poco a poco fue adquiriendo cada vez más intensidad hasta convertirse en la única autoridad suprema» ${ }^{26}$. Señala además que los mismos colegiales impulsaron este cambio de autoridad, pues así veían más protegidos sus intereses, dado que la protección real podía hacer más fácil la consecución de un buen empleo en puestos de la administración eclesiástica o laica, «ya que incluso en la primera en muchos casos correspondía al rey presentar a los candidatos a los cargos» ${ }^{27}$.

\section{LA REAL PROTECCIÓN}

La Real Protección fue acordada para el Colegio a partir de los Reyes Católicos $^{28}$, según se recoge en los estatutos de 1488 impresos en Bolonia, que renovaron los de $1377^{29}$. La Biblioteca Histórica de la Universidad Complutense conserva entre sus tesoros los Estatutos de 1488 en una impresión de finales del siglo XV: se trata del incunable Statuta Collegii Scholasticorum Hispanorum Bononiae, Bononiae: Justinianus de Rubería, sin fecha, hacia $1495-1500^{30}$, que ha sido señalado por Baltasar Cuart Moner en $1979^{31}$, y también examinado por Manuel Sánchez Mariana en 1995 en su nota "Un incunable desconocido entre los fondos de la Universidad Complutense" ${ }^{32}$. En este incunable de finales del siglo XV conservado en la Biblioteca Histórica de la Universidad Complutense puede leerse:

${ }^{26}$ Pérez Martín, Proles Aegidiana vol. I., 78.

27 Ibídem, nota 313 p. 79.

${ }^{28}$ Cuart Moner, "Los Estatutos del Colegio de San Clemente", 643.

${ }^{29}$ Pérez Martín, Proles Aegidiana vol. I., nota 77 p. 33.

30 Statuta Collegii Scholasticorum Hispanorum Bononiae, Bononiae: Justinianus de Rubería, sin fecha, hacia 1495-1500, Biblioteca Histórica de la Universidad Complutense Signatura BH MSS 101(2).

${ }^{31}$ Cuart Moner, "Los Estatutos del Colegio de San Clemente", nota 7 p. 634.

${ }^{32}$ La larga nota de Manuel Sánchez Mariana incluye la descripción del códice y las razones por las que cree que los estatutos del Colegio de Bolonia son un incunable: «En el fondo de códices procedentes del Colegio Mayor de San Ildefonso, que dio a conocer José Villa-Amil y Castro en el catálogo publicado en 1878, y que hoy, como en dicho año, se conservan en la Biblioteca del Noviciado con el número 101 de dicho catálogo hay un volumen que recoge varios textos de estatutos y constituciones de colegios y universidades, todos ellos manuscritos, excepto el que vamos a describir con detenimiento más adelante. El contenido general del volumen es el siguiente: a) Ordenario del Collegio contiguo a la yglesia catedral [de Toledo] (ff. 1-6v); b) [Statuta Collegii et Universitatis Parisiensis] (ff. 7-158v.); c) Constituciones Collegii Sanctae Crucis de Valladolid. 1494 (ff. 161-184); d) Constituciones del Colegio del Obispo de Palencia de Valladolid. 1502 (ff. 185-217); e) [Statuta Collegii scolasticorum Hispanorum Bononiae] (Impreso, s.l., s.i., s.a.) (ff. 219-253); f) [Statuta et Constituciones Collegii Saguntini. 1482-1491] (ff. 254--296). Se trata de un volumen de 296 folios en papel, en folio, recopilado de varios manuscritos sueltos quizá a principios del siglo XVI; algunos de estos textos de constituciones debieron servir a Cisneros para elaborar las ildefonsinas, o al menos esto es lo que opinaba un colegial del siglo XVIII que anotó en la guarda: «Sin disputa esta colección de Constituciones fue la que nro. Sto. Amo tuvo presente fara formar las nuestras. Exceptúa las de uno u otro Colegio, que creo pueden haver sido después insertas, chronologia visa». Llama enseguida la atención del que consulta el volumen el texto que hemos descrito en el apartado e), por ser el único impreso y por presentar todo el aspecto de haberlo sido en los primeros años de la imprenta. [...] No 


\section{Statutum XV}

Item quia summe credimus expedire quod aliquis princeps secularis et etiam aliquis sacro sancte romanae ecclesie cardinalis huius collegii et domus curam habeat specialem $\cdot$ ideo ferdinando et helisabeth hispaniarum regi et regine potentissimis et catholicis donec egerit in humanis postmodum vero serenissimis et excelentisimis regni castelle et legionis regi et regine est insolide $\cdot$ ac cardinali hispanie qui de regno castelle pro tempore fuerit et nullo tali hispano in collegio denorum cardinalium exente cardiali sabinensi quicumque pro tempore fuerit protectiones et defensionem committimus ${ }^{33}$.

A partir de los Reyes Católicos, la Monarquía hispánica no dejó nunca de velar por el Colegio de San Clemente. Dámaso de Lario reproduce una carta en italiano de la reina Juana y de su hijo el rey, reyes de Castilla, León, de Aragón, de una y otra Sicilia, de Jerusalén, etc., dirigida al Senado de Bolonia, fechada en Barcelona a 11 de marzo de 1519 y firmada por el rey, en la que aseguran que el Colegio siempre fue di gran cura, es decir de gran cuidado, para los reyes que les precedieron y para ellos. Los reyes agradecen al Senado su intervención para que los colegiales no fueran damnificados a raíz de una controversia surgida entre ellos y otra gente no especificada, y le encomiendan el cuidado del Colegio también para el futuro $^{34}$.

Seguramente Carlos $\mathrm{V}^{35}$ tuvo en aprecio al Colegio. Según relata Baltasar Cuart, en 1520 intentó -sin éxito- que los naturales del reino de Navarra fueran

cabía identificarlo con la edición de los Estatutos hecha en Bolonia en 1485 (de la que el único ejemplar existente en España está en la Seo de Zaragoza), ya que los Estatutos son posteriores, pues datan de 1487-88, según se lee en el texto. [...] Fue entonces cuando decidimos hacer un estudio de la tipografía; [...] Quedaba así identificado, con un grado de posibilidad muy alto, el lugar y el nombre del impresor: Bolonia, y Justinianus de Ruberia. Comunicamos el hallazgo con el especialista en incunables de la Biblioteca Nacional, Julián Martín Abad, quien repitió por su cuenta la investigación y confirmó el resultado, llegando incluso más allá al fechar la impresión, por sus características tipográficas y el uso por dicho impresor por esos años, entre 1495 y 1500. Parecía, por tanto, que se trataba de un incunable [...].» Manuel Sánchez Mariana, "Los Estatutos del Colegio español de Bolonia. Un incunable desconocido entre los fondos de la Universidad Complutense", en La biblioteca informa, $\mathrm{n}^{\circ} 8$ (25 de enero de 1995): 10-12, conservado como Separata en la Biblioteca Histórica de la Universidad Complutense.

33 Statuta Collegii Scholasticorum Hispanorum Bononiae, Bononiae: Justinianus de Rubería, sin fecha, hacia 1495-1500, F. 247r.

34 Ms. B. 3603, 138-140, conservado en la Biblioteca Archiginnasio de Bolonia, en Dámaso de Lario, "Conflictos y reformas del Colegio de España en Bolonia durante la impermeabilización habsburguesa", El Cardenal Albornoz y el Colegio de España IV, Studia albornotiana XV (Bolonia: Real Colegio de España, 1973): 501; Apéndice documental I, Carta de la reina y del rey "Alli Magnifici e amati e Devoti Nostre Confaloniero, et Quaranta della Città di Bologna", en Lario, "Conflictos y reformas del Colegio de España en Bolonia”, 570-571.

35 Sepúlveda, además de la vida de Gil Albornoz (véase nota 7), escribió también sobre las hazañas de Carlos V: Juan Ginés de Sepúlveda, De rebus gestis Caroli V. Liber primus, Edición, introducción y traducción de Elena Rodríguez Peregrina (Granada: Universidad de Granada, 1994); Juan Ginés de Sepúlveda, De rebus gestis Caroli V imperatoris et regis Hispaniae historia. Libri II-IX, Introducción, edición crítica, traducción de Elena Rodríguez Peregrina (Granada: Universidad de Granada, 1986). Véase 
aceptados en el Colegio ${ }^{36}$, mientras que Amando Represa habla de una carta en la que el monarca recomendó al rector y consiliarios del Colegio al bachiller Diego de Carrión $^{37}$. Estando en Bolonia, Carlos V le concedió su protección el 6 de enero de 1530 con ocasión de su visita a San Clemente. Al mes siguiente, el 24 de febrero, salió del Colegio para dirigirse a la basílica de San Petronio y ser coronado emperador por el papa Clemente VII. Una segunda visita de Carlos V a Bolonia tuvo lugar en la Epifanía de 1533. En esta ocasión, según relata Pérez Martín, los colegiales acudieron a él para la concesión de algunos privilegios. El emperador los remitió al papa, que prometió mucho, pero no hizo nada ${ }^{38}$.

La protección real fue recogida también en los Estatutos posteriores a los de $1488^{39}$ : en el estatuto 27 distinción cuarta de los de $1538^{40}$ y de $1558^{41}$, que trata de los protectores del Colegio; en el estatuto 31 distinción cuarta de los Estatutos de $1628^{42}$ y, con la misma fórmula, en el estatuto 19 distinción cuarta de los Estatutos de $1648^{43}$, donde puede leerse que se confía el Colegio a la fe y patrocinio del clarísimo y

también el artículo de Baltasar Cuart Moner, "Los Romanos, los Godos y los Reyes Católicos a mediados del siglo XVI: Juan Ginés de Sepúlveda y su De Rebus Gestis Caroli V Imperatoris et Regis Hispaniae", en Studia Histórica: Historia Moderna, vol. 10 (1992): 61-87.

${ }^{36}$ Cuart Moner, "Los Estatutos del Colegio de San Clemente", nota 7 p. 667.

37 Represa, "El Colegio Español de Bolonia", 393.

38 Pérez Martín, Proles Aegidiana, vol. I., 79.

${ }^{39}$ Roversi, "L’azione di papa Lambertini a favore del Collegio di Spagna”, 537.

${ }^{40}$ Item, ut pium, \& sanctum opus, optimi viri, nationis Hispaniae, liberalitate, ad commoditatem Hispanorum, in aliena regione conditum fauore, \& praesidio conseruetur eorum, quos in primis fas est, eius gentis dignitati, atque commodis consulere, idcirco Hispaniae, castellaeque clarissimi, \& catholici Regis, \& Cardinalis Hispani ex regno Castellae, qui Pontificem Ro. eiusve curiam assectabitur, aut si nullus talis fuerit in curia, eius, qui titulo sanctae Sabinae fuerit, fidei, ac patrocinio Collegium committimus... (Biblioteca Archiginnasio de Bolonia, 17.R.IV.13: Statuta Collegii Hispanorum Bononiae, M.D.XXXVIII., Quarta Distinctio Statutum XXVII f. XXXVIr.).

${ }^{41}$ Item, ut pium \&o sanctum opus, optimi uiri, nationis Hispaniae, liberalitate, ad commoditatem Hispanorum, in aliena regione conditum fauore, \& praesidio conseruetur eorum, quos in primis, fas est, eius gentis dignitati, atque commodis consulere, idcirco Hispaniae, castellaeque clarissimi, \& catholici Regis, \& Cardinalis Hispani ex regno castellae, qui Pontificem Ro. eiusue curiam assectabitur, aut si nullus talis fuerit in curia, eius, qui titulo sanctae Sabinae fuerit, fidei, ac patrocinio collegium committimus... (Biblioteca Archiginnasio de Bolonia, 17.R.IV.12: Statuta Collegii Hispanorum Bononiae. Bononiae Antonius Giaccarellus, \& Peregrinus Bonardus focii Excudebant. M. D. LVIII, Quarta Distinctio Statutum XXVII f. XXXVIIr.).

42 Item ut pium, \& sanctum opus optimi viri, nationis Hispaniae liberalitate ad commoditatem Hispanorum in aliena regione conditum, fauore, \& praesidio conseruetur, eorum, quos in primis fas est, eius gentis dignitati, atque commodis consulere: idcirco Hispaniae, Castellaeque; Clarissimi, \& catholici Regis, \& Cardinalis Hispani ex Regno Castellae, qui Pontificem Romanum eiusue curiam assectabitur, aut si nullus talis fuerit in Curia, eius, qui titulo Sanctae Sabinae fuerit, fidei, ac patrocinio Collegium committimus... (Biblioteca Archiginnasio de Bolonia, 17 O III 1 (op. 06): Statuta almi et perinsignis Collegii Maioris S.Clementis Hispanorum Bononiae conditi. Bononiae, M.DC.XXVIII. Typis Clementis Ferronij. Superiorum permissu, Quarta Distinctio Statutum Trigesimum Primum, 98).

43 ... Idcirco Hispaniae, Castellaeque; clarissimi, ac Catholici Regis fidei, ac patrocinio, \& Cardinalis Hispani, qui Pontificem Romanum eiusue Curiam assectabitur, itaut Castellanus, \& in concursu omnium vetustissimus coeteris praeferatur deinde Aragonensis; postremo Lusitanus, \& si nullus talis fuerit in Curia eius, qui tituli Sanctae Sabinae sit, fidei ac Protectioni Collegium commitimus... (BNE, 2/56002 (1): Statuta almi et perinsignis Collegii 
católico rey de Hispania y Castilla, y a la fe y protección de un cardenal hispano. Los sucesivos monarcas de la casa de Habsburgo renovaron la protección, según señaló en 1695 el Doctor don Salvador Silvestre de Velasco y Herrera en su Compendio de la Nobilissima Fundación, y Privilegios del Colegio Mayor de Señor S. Clemente de los Españoles de Bolonia $^{44}$.

Felipe $\mathrm{II}^{45}$ confirmó la protección en Madrid el 6 de febrero de 1563. El Rey ${ }^{46}$, después de haber reconocido que del Colegio de San Clemente fundado por Gil de Albornoz «han salido, y de continuo salen personas doctas, y eminentes, de quien nos, y los Reyes nuestros antecesores nos havemos servido en negocios, y cargos importantes, asi en estos Reynos, como en los Reynos de Napoles, y Sicilia, y estado de Milan», a petición del Rector y de los colegiales aceptó su protección con estas palabras:

Y assi por la presente aceptamos por nos, y en nombre de los Reyes nuestros successores, que por tiempo fueren, la Protección del dicho Collegio, y recevimos, y tomamos el dicho Collegio de S. Clemente de los Espagnoles, y a las personas y bienes del debajo nuestra Proteccion, y amparo, y mandamos, que les sean guardados todos sus privilegios, franquezas, y libertades, que por nos y los Reyes nuestros antecesores les huvieren sido concedidas, y les mandamos dar, y daremos todo favor, y ayuda para que las Constituciones, y Estatutos, y lo de mas ordenado por el dicho Fundador sea guardado, para que ni por los dichos Rector, y Collegiales, ni por otra persona alguna se venga ni vaya contra ellas ${ }^{47}$.

Los monarcas de la Casa de Austria ${ }^{48}$ que sucedieron a Felipe II también consideraron importante el vínculo con el Colegio: Felipe III aceptó su protección el 9 de junio de $1603^{49}$; Felipe IV la aceptó por Real Cédula dada en Monzón el 5 de

Maioris Sancti Clementis Hispanorum Bononiae Conditi. Bononiae, M.DC.XLVIII. Ex Typographia Haeredis Benatij. Superiorum permissu, Quarta Distinctio Statutum Decimumnonum, 55).

${ }^{44}$ Compendio de la Nobilissima Fundación, y Privilegios del Colegio Mayor de Señor S. Clemente de los Españoles de Bolonia, espejo de los demás Colegios Mayores, y Menores de España, e Italia. Fundado por el Eminentissimo Señor Cardenal de la Santa Iglesia de Roma D. Gil Carrillo de Albornoz, Obispo de Santa Sabina, Arzobispo de Toledo, Gran Canciller de Castilla, y Legado General de toda Italia... por el Doctor Don Salvador Silvestre de Velasco y Herrera, Con Licencia, Por Juan Francisco de Blas, Impressor Mayor, Año de 1695, 302 (BNE, 3/61319).

${ }^{45}$ Sobre las relaciones de Felipe II con Italia véase el volumen de Manuel Rivero Rodríguez, Felipe II y el gobierno de Italia (Madrid: Sociedad Estatal para la Conmemoración de los Centenarios de Felipe II y Carlos V, 1998).

${ }^{46}$ El ya citado Juan Ginés de Sepúlveda (véase notas 7 y 33) fue también autor de una obra sobre la vida de Felipe II: De rebus gestis Philippi regis Hispaniae, 1601 (BNE, Mss/2046).

${ }^{47}$ Don Phelipe Segundo deste nombre, BNE 2/56002(4).

48 Sobre los monarcas de la Casa de Austria en el siglo XVII véase el artículo de José Martínez Millán, "Evolución política y religiosa de la Monarquía hispana durante el siglo XVII", en Carthaginensia: Revista de estudios e investigación, vol. 31, nº 59 (2015): 215-250.

${ }^{49}$ Roversi, "L'azione di papa Lambertini a favore del Collegio di Spagna", 537. También citada en las Reales Cédulas de Felipe IV y Carlos II. 
marzo de $1626^{50}$; Carlos II la aceptó el 24 de octubre de $1684^{51}$. En el caso del primer monarca de la dinastía Borbón ${ }^{52}$ la importancia acordada a la institución fue máxima, hasta el punto que incluso llegó a visitarla: Felipe V realizó el 23 de julio de $1702^{53}$ una visita al Colegio de San Clemente, visita que fue celebrada por Don Gregorio de Parga y Bassadre, antiguo rector del Colegio y Catedrático de Vísperas de Cánones en la Universidad de Bolonia, con el texto conmemorativo titulado El Fenix de Bolonia (Bolonia, 1702) ${ }^{54}$. Sin embargo, el rey no aceptó la protección al Colegio en esta ocasión, sino pocos meses después por la Cédula firmada por la reina María Luisa Gabriela de Saboya en Madrid a 28 de noviembre de $1702^{55}$.

\section{LAS RELACIONES DEL COLEGIO CON LA MONARQUÍA}

En la guerra de sucesión el Real Colegio se posicionó a favor de Felipe V. Cuando las tropas imperiales llegaron a las inmediaciones de Bolonia e intentaron imponer la obediencia al archiduque Carlos a los colegiales, éstos se opusieron ${ }^{56}$ y tuvieron que esconder los bienes del Colegio en varios conventos de Bolonia, quedando cerrado el Colegio entre 1708 y 1714. Terminada la guerra, con la pérdida de los territorios italianos, San Clemente se convirtió en cambio en un centro estratégicamente importante para la Corona, por el que también transitaban las tropas españolas destinadas a otros lugares ${ }^{57}$.

Según el Centón de noticias de Borrajo y Giner de los Ríos, los reyes no solo concedieron al Colegio el título de Real, sino también la validez de los grados de Doctor conseguidos en la Universidad de Bolonia ${ }^{58}$. Esto adquirió especial relevancia sobre todo a partir de la conocida Pragmática de Felipe II de 22 de noviembre de 1559, que prohibió a los «súbditos, i Naturales, Eclesiasticos, i Seglares, Frailes, i Clerigos, ni otros algunos» ir o salir de sus reinos a estudiar, enseñar, aprender, estar, o residir en Universidades, Estudios o Colegios fuera de sus reinos. Había muy pocas

${ }^{50}$ Don Phelipe Quarto deste nombre, BNE 2/56002(5).

${ }^{51}$ Don Carlos Segundo deste nombre, BNE 2/56002(6).

${ }^{52}$ Sobre los principales cambios acontecidos en la Monarquía española con la nueva dinastía véase el volumen de José Martínez Millán, Concepción Camarero Bullón, Marcelo Luzzi Traficante, La Corte de los Borbones: Crisis del modelo cortesano, 3 vols. (Madrid: Ediciones Polifemo, 2013).

${ }^{53}$ González-Varas Ibáñez, Dietro il muro del Collegio di Spagna, 83.

${ }^{54}$ El Fenix de Bolonia, en ocasión de celebrar la venida de Felipe V. a Italia El Colegio Mayor de Españoles de dicha Ciudad Consagrale a la Magestad del muy alto, y muy poderoso Señor Don Felipe V. de Borbon Rey de las Españas, y del Nuevo Mundo, Nuestro Señor. Don Gregorio de Parga, y Bassadre Natural de Santiago de Galicia, Rector que ha sido, y oy Colegial de dicho Colegio; y Cathedratico de Visperas de Canones de esta Universidad. En Bolonia. M.DCCII. En la Imprenta de Pier Maria Monti. Con licencia de Superiores. Biblioteca Archiginnasio de Bolonia, 17.C.V.29.

55 Don Phelipe Quinto deste nombre, BNE 2/56002(7).

${ }^{56}$ Borrajo y Herrera, H. Giner de los Ríos, El Colegio de Bolonia. Centón de noticias, 10.

${ }^{57}$ Pérez Martín, Proles Aegidiana vol. I., 24 y nota 41 p. 24.

58 Borrajo y Herrera, H. Giner de los Ríos, El Colegio de Bolonia. Centón de noticias, 8. 
excepciones en la Pragmática, y éstas estaban constituidas por las universidades de Roma, de Nápoles, de Coímbra y de Bolonia, en este último caso solo si los estudiantes eran colegiales de San Clemente ${ }^{59}$.

El Colegio de San Clemente también procuraba mantener los mismos privilegios de los Colegios peninsulares. Por ejemplo, al entrar en vigor la Pragmática dictada por Felipe IV el 10 de febrero de 1623, por la que las pruebas para calificar la limpieza de sangre hechas por la Inquisición, Consejo de Órdenes Militares y los seis Colegios peninsulares tenían valor de pruebas definitivas, diversos colegiales y el Colegio mismo solicitaron el mismo privilegio, que obtuvieron el 14 de mayo de $1624^{60}$.

Las visitas reales a San Clemente como las de Carlos V tuvieron que ser algo especial, si se considera que el libro de Ceremonias y Costumbres del Colegio ${ }^{61}$ de 1627 no guarda un protocolo específico para la recepción de los reyes mientras sí prevé, en cambio, un ceremonial específico para recibir a otras personalidades como Cardenales, Embajadores del Rey en Roma, Gobernadores de Milán, Virreyes de Nápoles, Grandes de España, Vicelegados y Confalonieres de Bolonia ${ }^{62}$.

Sin embargo, la «presencia» de los reyes perduraba en el Colegio, y en ocasión del fallecimiento de algunos monarcas -Felipe II, Felipe III, Felipe IV, Carlos II, Felipe V, Carlos III- el Colegio celebró ceremonias fúnebres que han sido detalladas por un estudio de Primo Bertrán Roigé ${ }^{63}$. En estas ocasiones sí había que respetar un ritual previsto por el libro de Ceremonias: «Quando mueren los Reyes de España, suele el Collegio dar sotanillas de bayeta, y sombreros de luto a los Collegiales, y vestir los criados, y cubrir la carroza de bayeta, y en la Yglesia se haze vn Tumulo moderado para celebrar las Exequias». ${ }^{64} \mathrm{Si}$ bien las visitas reales al Colegio fueron

${ }^{59}$ Lario, "Sobre los orígenes del burócrata moderno", 20-21.

60 Ibídem, 73.

${ }^{61} \mathrm{La}$ Biblioteca Archiginnasio de Bolonia guarda la edición de 1627 de las Ceremonias y Costumbres usadas, y guardadas, Y que se han de usar, y guardar en este insigne Collegio mayor de S. Clemente de los Españoles de Bolonia, En Bolonia por Clemente Ferroni 1627, en la Miscellanea de la Biblioteca Archiginnasio con Signatura 17 O III 1 (op. 07). La Biblioteca Nacional de España conserva la edición de 1706 en el volumen Statuta Collegii Maioris S. Cleme. con Signatura 2/56002. Ambas ediciones de las Ceremonias y costumbres..., es decir la de 1627 y la de 1706, han sido señaladas por Batllori, "El Colegio de España en Bolonia", nota 2 p. 641.

${ }^{62}$ Ceremonias y Costumbres usadas y guardadas, 22-24.

${ }^{63}$ Primo Bertrán Roigé, "Ceremonias fúnebres por los monarcas españoles en el Colegio de San Clemente de los españoles en el Colegio de San Clemente en Bolonia. Notas y documentos", en Evelio Verdera y Tuells (ed.), El Cardenal Albornoz y el Colegio de España V, Studia albornotiana XXXVI (Bolonia: Real Colegio de España, 1979): 402-423. Sobre el ceremonial en la época de los Austrias véase también el artículo de Ignacio José García Zapata, Miguel José López-Guadalupe Pallarés, “El ceremonial en el Real Colegio de España en Bolonia: ritos y funciones en memoria de la Monarquía hispánica de los Austrias", en Potestas. Revista de Estudios del Mundo Clásico e Historia del Arte nr. 12 (junio 2018): 105-120.

${ }^{64}$ Ceremonias y Costumbres usadas y guardadas, 25. 
escasas $^{65}$, la Corona intervino sobre el Colegio a través de sus representantes: antes de la guerra de sucesión a través del virrey de Nápoles, del gobernador de Milán y del Embajador ante la Santa Sede; después de la guerra a través del embajador en Roma ${ }^{66}$.

En el siglo XVIII las intervenciones reales se intensificaron y estuvieron relacionadas con el envío de visitadores en situaciones de dificultad o desorden del Colegio ${ }^{67}$. Miquel Batllori menciona un caso importante de visitador de nombramiento regio: es en 1757 el de Francisco Pérez Bayer ${ }^{68}$, erudito valenciano, canónigo de Barcelona y más tarde de Toledo. El caso Pérez Bayer ha sido estudiado también por Carlos Nieto Sánchez ${ }^{69}$, que escribe que fueron los mismos colegiales quienes le propusieron como visitador, después de su paso por la biblioteca del Colegio en 1754, época en la que en el Colegio se había producido un descubierto de unos miles de libras. Por solicitud de los colegiales en 1757 el rey le nombró visitador, con el fin de que examinase la conducta del rector y los demás colegiales, y tomara las providencias que considerara necesarias para la observancia de los estatutos. Estas órdenes le fueron transmitidas por el embajador de España en Roma, el cardenal Portocarrero, en quien el mismo Pontífice había delegado la autoridad sobre la visita. El caso Pérez Bayer es de señalar porque, en general ${ }^{70}$, los visitadores habían sido designados por la autoridad eclesiástica. Los visitadores ordinarios eran el obispo de Bolonia, el prior de San Miguel del Bosque y el arcediano de Bolonia; las visitas extraordinarias eran ordenadas por el papa $^{71}$.

\section{EL PODER DE LA MONARQUÍA}

La Iglesia mantenía antiguamente un fuerte poder sobre el Colegio. Prueba de ello es que, como anteriormente se ha dicho, los reyes de España no eran las únicas figuras previstas para la protección del Colegio en los antiguos Estatutos, donde aparece la figura del cardenal protector ${ }^{72}$ en la ya mencionada Distinción cuarta. Este cargo correspondía al Cardenal de Castilla residente en la Curia romana, y en su defecto al Cardenal de Aragón, o lusitano o, si no hubiera ninguno de ellos, al que

\footnotetext{
${ }^{65}$ Solo tres monarcas españoles visitaron el Colegio: Carlos V en 1530 y 1533; Felipe V en 1702; Juan Carlos de Borbón en 1988. Solo Carlos V y Juan Carlos de Borbón aceptaron la protección en la capilla de San Clemente. Véase Los reyes de España en Bolonia (Bolonia: Real Colegio de España, 1988) 4.

${ }^{66}$ Pérez Martín, Proles Aegidiana vol. I., 78-79.

${ }^{67}$ Pérez Martín, Proles Aegidiana vol. I., nota 312 p. 79. Véase también los casos mencionados por Represa, "El Colegio Español de Bolonia".

68 Batllori, "El Colegio de España en Bolonia", 643.

${ }^{69}$ Carlos Nieto Sánchez, San Clemente de Bolonia (1788-1889) (Madrid: Universidad Carlos III, 2012), 44-60.

${ }^{70}$ Dámaso de Lario señala el caso del nombramiento del auditor Francisco de la Peña por Felipe III, pero no queda claro si este auditor realizó su visita al Colegio. Lario, "Conflictos y reformas del Colegio de España en Bolonia", 518.

${ }_{71}$ Pérez Martín, Proles Aegidiana vol. I., 75.

72 Ibídem, 75-77.
} 
tuviera el título de Santa Sabina. Su intervención era en calidad de defensor, conservador y juez en la resolución tanto de casos y asuntos corrientes en la vida de la institución como de casos criminales. Sin embargo, esta figura de cardenal protector desapareció en 1761 tras la muerte del arzobispo Joaquín Fernández de Portocarrero. Después de su fallecimiento la protección del Colegio quedó prácticamente en manos de la Monarquía; cuando en 1777 se publicó el decreto que reformaba los colegios mayores de la península, el de Bolonia pudo subsistir por estar fuera de España ${ }^{73}$.

Nieto Sánchez, en su volumen titulado San Clemente de Bolonia (1788-1889), explica:

Tras el deceso [del arzobispo], el Rey Carlos III, no habiendo ningún cardenal español en Roma, recomendó al rector y a los colegiales que acudiesen a su embajador ante el Papa, Manuel de Roda. Desde este momento puede decirse que desaparece la intervención directa del cardenal protector. A partir de ahora, y aunque nominalmente siguió designándose un protector perteneciente al Sacro Colegio cardenalicio, la autoridad protectora efectiva fue el embajador o agente diplomático del Rey de España ante la Corte Pontificia. ${ }^{74}$

Como colofón de ello estarían los reformados Estatutos de $1876^{75}$, fecha en la que la expansión del Reino de Italia ya había reducido el territorio y el poder del Estado Pontificio. Estos Estatutos, publicados por Borrajo-Giner en el Centón de Noticias de 1880, establecieron que es al Rey de España, y solo a él, a quien competen la conservación, protección y alto patrocinio del Real Colegio Mayor de San Clemente de los Españoles de Bolonia y el nombramiento del rector ${ }^{76}$. El Rey Juan Carlos aseguró su protección en ocasión de la visita a Bolonia de 1988.

\footnotetext{
${ }^{73}$ Sobre la historia del Colegio entre los siglos XVIII y XX véanse los artículos: Rinaldo Froldi, "El Colegio de España de Bolonia y la literatura española", Edición digital a partir de Actas del Séptimo Congreso de la Asociación Internacional de Hispanistas: Venecia del 25 al 30 de agosto de 1980 (Roma: Bulzoni, 1981): 315-324; Carlos Nieto Sánchez, "El Colegio hispánico de Bolonia: crisis y supervivencia decimonónica de una institución educativa", 1-16, https://www.ucm.es/data/cont/media/www/pag-13888/CarlosNieto.pdf (consultado el 30 de octubre de 2018).

${ }^{74}$ Nieto Sánchez, San Clemente de Bolonia (1788-1889), 24-25.

${ }^{75}$ Los Estatutos de 1876, que aseguraron que la Casa Hispánica fundada por Albornoz en 1364 pudiese mantenerse bajo mandato español en el recién constituido Reino de Italia, se habían aprobado por la Junta Consultiva de Fundaciones el 10 de octubre de 1876, y fueron confirmados por el Consejo de Instrucción Pública de 27 de abril de 1877. Nieto Sánchez, San Clemente de Bolonia (17881889), 316.

${ }^{76}$ Pérez Martín, Proles Aegidiana vol. I., 80; Estatutos, artículos 1 y 12, en Borrajo y Herrera, H. Giner de los Ríos, El Colegio de Bolonia. Centón de noticias, 125 y 127.
} 


\section{CONCLUSIONES}

En conclusión, el Colegio de San Clemente de Bolonia acogió desde sus orígenes a estudiantes hispanos que tuvieron una misma formación universitaria, y que, desde distintos territorios peninsulares, compartieron una vida común, tal como lo quiso su fundador el Cardenal Gil Albornoz. La protección real concedida por la Monarquía desde los Reyes Católicos, pone de manifiesto la importancia y el interés que la Corona ha tenido a lo largo de los siglos en el Real Colegio Mayor de San Clemente. Los acontecimientos históricos han dado a San Clemente una caracterización española cada vez mayor y un progresivo aumento de la autoridad de la Monarquía hispánica en detrimento del poder ejercido por la Iglesia. Las sucesivas reformas de los Estatutos del Real Colegio de los Españoles han recogido esta creciente autoridad, y las visitas reales, si bien no frecuentes, la han de alguna manera confirmado y asegurado. 


\section{BIBLIOGRAFÍA}

Miquel Batllori S.I., "El Colegio de España en Bolonia a fines del siglo XVIII”, Studia albornotiana XII (Bolonia: Real Colegio de España, 1972): 639-669.

Vicente Beltrán de Heredia, Primeros estatutos del Colegio Español de S. Clemente en Bolonia, en «Hispania Sacra» 11 (1958): 409-426.

Primo Bertrán Roigé, "Ceremonias fúnebres por los monarcas españoles en el Colegio de San Clemente de los españoles en el Colegio de San Clemente en Bolonia. Notas y documentos", en Evelio Verdera y Tuells (ed.), El Cardenal Albornoz y el Colegio de España V, Studia albornotiana XXXVI (Bolonia: Real Colegio de España, 1979): 402-423.

Biblioteca Archiginnasio de Bolonia, 17.C.V.29: El Fenix de Bolonia, en ocasión de celebrar la venida de Felipe V. a Italia El Colegio Mayor de Españoles de dicha Ciudad Consagrale a la Magestad del muy alto, y muy poderoso Señor Don Felipe V. de Borbon Rey de las Españas, y del Nuevo Mundo, Nuestro Señor. Don Gregorio de Parga, y Bassadre Natural de Santiago de Galicia, Rector que ha sido, y oy Colegial de dicho Colegio; y Cathedratico de Visperas de Canones de esta Universidad. En Bolonia. M.DCCII. En la Imprenta de Pier Maria Monti. Con licencia de Superiores.

Biblioteca Archiginnasio de Bolonia, 17 O III 1: Miscellanea.

Biblioteca Archiginnasio de Bolonia, 17 O III 1(op.04): Historia de bello administrato in Italia per annos XV \& confecto ab Illustriss. ac Reuerendiss. D.D. Aegidio Albornotio $S \cdot \mathrm{R} \cdot \mathrm{C} \cdot \mathrm{CARDIN} A L I$ Pont. Max. Innocentij VI, qui Auenione tunc residebat, Legato. Sacri, \& perinsignis Collegij maioris S. Clemente Hispanorum, quod Bononiae est, Fundatore. Pro vindicandis in libertatem omnibus Urbibus, quae antea in ditiones erant, et imperio Sanctae Romanae Ecclesiae. A Ioanne Genesio Sepulveda Hispano eiusdem Collegijalumno scripta. BONONIAE MDCXXVIII. Typis Clementis Ferronij.

Biblioteca Archiginnasio de Bolonia, 17 O III 1(op.05): Illustriss. Ac reverendiss. D. Aegidii Albornotii S.R.E. Cardinales Totius Italiae Legati, Archiepiscopi Toletani, ac Collegij maioris Hispanorum Bononiae fundati Institutoris Testamentum, Bononiae MDCXXVIII. Typis Clementis Ferronij.

Biblioteca Archiginnasio de Bolonia, 17 O III 1(op.06): Statuta Sacri et Perinsignis Collegii Maioris S. Clementis Hispanorum Bononiae conditi, BONONIAE M.DC:XXVIII. Typis Clementis Ferronij. 
Biblioteca Archiginnasio de Bolonia, 17 O III 1(op. 07): Ceremonias y Costumbres usadas, y guardadas, $Y$ que se han de usar, y guardar en este insigne Collegio mayor de $S$. Clemente de los Españoles de Bolonia, En Bolonia por Clemente Ferroni 1627.

Biblioteca Archiginnasio de Bolonia, 17.R.IV.12: Statuta Collegii Hispanorum Bononiae. Bononiae Antonius Giaccarellus, \& Peregrinus Bonardus focii Excudebant. M. D. LVIII.

Biblioteca Archiginnasio de Bolonia, 17.R.IV.13: Statuta Collegii Hispanorum Bononiae, M.D.XXXVIII.

Biblioteca Histórica de la Universidad Complutense, BH MSS 101(2): Statuta Collegii Scholasticorum Hispanorum Bononiae, Bononiae: Justinianus de Rubería, sin fecha, hacia 1495-1500.

Biblioteca Nacional de España BNE, 2/56002: Statuta Collegii Maioris S. Cleme.

BNE, 2/56002 (1): Statuta almi et perinsignis Collegii Maioris Sancti Clementis Hispanorum Bononiae conditi. Bononiae, M.DC.XLVIII. Ex Typographia Haeredis Benatij.

BNE, 2/56002 (4): Don Phelipe Segundo deste nombre.

BNE, 2/56002 (5): Don Phelipe Quarto deste nombre.

BNE, 2/56002 (6): Don Carlos Segundo deste nombre.

BNE, 2/56002 (7): Don Phelipe Quinto deste nombre.

BNE, 3/61319: Compendio de la Nobilissima Fundación, y Privilegios del Colegio Mayor de Señor S. Clemente de los Españoles de Bolonia, espejo de los demás Colegios Mayores, y Menores de España, e Italia. Fundado por el Eminentissimo Señor Cardenal de la Santa Iglesia de Roma D. Gil Carrillo de Albornoz, Obispo de Santa Sabina, Arzobispo de Toledo, Gran Canciller de Castilla, y Legado General de toda Italia... por el Doctor Don Salvador Silvestre de Velasco y Herrera, Con Licencia, Por Juan Francisco de Blas, Impressor Mayor, Año de 1695.

BNE, MSS/2046: Juan Ginés de Sepúlveda, De rebus gestis Philippi regis Hispaniae, 1601.

BNE, U/5579: Proles Aegidiana seu Catalogus Illust. Virorum, Qui ex Almo, \& Perinsigni Collegio Maiori Sancti Clementis Hispanorum. Auspicijs bonae memoriae Illustriss. \& Reuerendiss. D.D. Aegidii S.R.E. Cardinalis Albornotij Episcopi Sabinensis, Archiepiscopi Toletani, \& totius Italiae Legati generalis, Bononiae condito buc usque in lucem prodiere. Opus sane curiosum: collectum a D. Ioanne de Pineda Hurtado de Mendoza Hispalensi, eiusdem Collegij alumno, \& institutionum 
Imperialium antecessore. BONONIAE, Apud Haeredem Bartholomaei Cochij, M.DC.XXIIII, Superiorum permissu.

Pedro Borrajo y Herrera, Hermenegildo Giner de los Ríos, El Colegio de Bolonia. Centón de noticias relativas a la fundación bispana de San Clemente, por los excolegiales D. Pedro Borrajo y Herrera y D. Hermenegildo Giner de los Ríos (Madrid, 1880).

El Cardenal Albornoz y el Colegio de España I, Edición y Prólogo de Evelio Verdera y Tuells, Studia Albornotiana XI (Bolonia: Real Colegio de España, 1972).

Francesco Cavazza, Le scuole dell'antico Studio bolognese, Ristampa anastatica dell'edizione di Milano, 1896, eseguita per gentile concessione della Casa Editrice U. Hoepli di Milano (Sala Bolognese: Arnaldo Forni Editore, 1987).

Baltasar Cuart Moner, "Colegiales y burócratas: El caso del Colegio de San Clemente de los españoles de Bolonia en la primera mitad del s. XVI", en Studia histórica. Historia moderna, $\mathrm{n}^{\circ} 1$ (1983): 65-93.

Baltasar Cuart Moner, "Los Estatutos del Colegio de San Clemente como fuente para una aproximación al estudio de la burocracia (1485-1558)", en El Cardenal Albornoz y el Colegio de España IV, Studia Albornotiana XXXV (Bolonia: Real Colegio de España, 1979): 579-696.

Baltasar Cuart Moner, "Los Romanos, los Godos y los Reyes Católicos a mediados del siglo XVI: Juan Ginés de Sepúlveda y su De Rebus Gestis Caroli V Imperatoris et Regis Hispaniae", en Studia Histórica: Historia Moderna, vol. 10 (1992): 61-87.

António Domingues de Sousa Costa, Portugueses no Colégio de S. Clemente e Universidade de Bolonba durante o século XV, vol. I (Bolonia: Real Colegio de España, 1990).

Rinaldo Froldi, "El Colegio de España de Bolonia y la literatura española", Edición digital a partir de Actas del Séptimo Congreso de la Asociación Internacional de Hispanistas: Venecia del 25 al 30 de agosto de 1980 (Roma: Bulzoni, 1981): 315324.

Ignacio José García Zapata, Miguel José López-Guadalupe Pallarés, “El ceremonial en el Real Colegio de España en Bolonia: ritos y funciones en memoria de la Monarquía hispánica de los Austrias", en Potestas. Revista de Estudios del Mundo Clásico e Historia del Arte nr. 12 (junio 2018): 105-120.

Ignacio González-Varas Ibáñez, Dietro il muro del Collegio di Spagna (Bologna: CLUEB, 1998). 
Dámaso de Lario, "Conflictos y reformas del Colegio de España en Bolonia durante la impermeabilización habsburguesa", en El Cardenal Albornozy el Colegio de España IV, Studia albornotiana XV (Bolonia: Real Colegio de España, 1973): 497-577.

Dámaso de Lario, Sobre los orígenes del burócrata moderno. El Colegio de San Clemente de Bolonia durante la impermeabilización habsburguesa (1568-1659), Studia Albornotiana XLIII (Bolonia: Real Colegio de España, 1980).

Dámaso de Lario, "La Universidad de Bolonia y el Colegio de España en el tránsito de los siglos XVI al XVII", en Estudis: Revista de historia moderna, no 8 (19791980): 7-23.

Giuseppe Marchini, "Il Collegio di Spagna, edificio monumentale", en Studia Albornotiana XXXVI (Bolonia: Real Colegio de España, 1979): 7-21.

Berthe Marie Marti, The Spanish College at Bologna in the Fourteenth Century (Philadelphia: University of Carolina Press, 1966).

Francisco Martín Hernández, "Influencia del Colegio de San Clemente de Bolonia en los Colegios mayores españoles", en El Cardenal Albornoz y el Colegio de España II, Edición y Prólogo de Evelio Verdera y Tuells, Studia Albornotiana XI (Bolonia: Real Colegio de España, 1972): 239-260.

Francisco Martín Hernández, "La influencia de los Colegios mayores españoles en la fundación y primer desarrollo de los americanos", en Estudios de historia social y económica de América, no 16-17 (1998): 9-22.

José Martínez Millán, Concepción Camarero Bullón, Marcelo Luzzi Traficante, La Corte de los Borbones: Crisis del modelo cortesano, 3 vols. (Madrid: Ediciones Polifemo, 2013).

José Martínez Millán, "Evolución política y religiosa de la Monarquía hispana durante el siglo XVII", en Carthaginensia: Revista de estudios e investigación, vol. 31, n 59 (2015): 215-250.

Federigo Melis, "Sul finanziamento degli allievi portoghesi del Real Colegio di Spagna di Bologna nel XV secolo", en El Cardenal Albornoz y el Colegio de España III, Studia Albornotiana XIII (Bolonia: Real Colegio de España, 1973): 419-434.

Carlos Nieto Sánchez, "El Colegio hispánico de Bolonia: crisis y supervivencia decimonónica de una institución educativa", 1-16, en 
https://www.ucm.es/data/cont/media/www/pag-13888/CarlosNieto.pdf (consultado el 30 de octubre de 2018).

Carlos Nieto Sánchez, San Clemente de Bolonia (1788-1889) (Madrid: Universidad Carlos III, 2012).

Manuel Parada López de Corselas (ed.), Domus hispánica. El Real Colegio de España y el cardenal Gil de Albornoz en la Historia del Arte (Bologna: Bononia University Press, 2018).

Antonio Pérez Martín, Proles Aegidiana vol. I., Studia Albornotiana XXXI (Bolonia: Real Colegio de España, 1979).

Antonio I. Pini, Studio, università e città nel medioevo bolognese (Bologna: CLUEB, 2005).

Amando Represa, "El Colegio Español de Bolonia, según la documentación de Simancas", Studia Albornotiana XII (Bolonia: Real Colegio de España, 1972): 391-399.

Los reyes de España en Bolonia (Bolonia: Real Colegio de España, 1988).

Manuel Rivero Rodríguez, Felipe II y el gobierno de Italia (Madrid: Sociedad Estatal para la Conmemoración de los Centenarios de Felipe II y Carlos V, 1998).

Giancarlo Roversi, "L'azione di papa Lambertini a favore del Collegio di Spagna e la controversa Visita apostolica del 1741", El Cardenal Albornoz. y el Colegio de España, Studia albornotiana XII (Bolonia: Real Colegio de España 1972): 523637.

Manuel Sánchez Mariana, "Los Estatutos del Colegio español de Bolonia. Un incunable desconocido entre los fondos de la Universidad Complutense", en La biblioteca informa, $\mathrm{n}^{\mathrm{o}}$ 8, (25 de enero de 1995): 10-12.

Juan Ginés de Sepúlveda, De rebus gestis Caroli $V$ imperatoris et regis Hispaniae historia. Libri II-IX, Introducción, edición crítica, traducción de Elena Rodríguez Peregrina (Granada: Universidad de Granada, 1986).

Juan Ginés de Sepúlveda, De Rebus Gestis Caroli V. Liber primus, Edición, introducción y traducción de Elena Rodríguez Peregrina (Granada: Universidad de Granada, 1994).

Albano Sorbelli, Storia della Università di Bologna, Volume I Il Medioevo (secc. XI-XV) (Bologna: Nicola Zanichelli Editore, 1944). 
Giovanni de Vergottini, Lo Studio di Bologna, l'Impero, il Papato, Ristampa dell'edizione dell'Università degli Studi di Bologna, 1954 (Spoleto: Centro Italiano di Studi sull'Alto Medioevo, 1996).

Recibido: 31 de julio de 2018 Aprobado: 20 de octubre de 2018 